Original Article

\title{
DESIGN AND DEVELOPMENT OF SELF-MICROEMULSIFYING DRUG DELIVERY SYSTEMS (SMEDDS) OF TELMISARTAN FOR ENHANCEMENT OF IN VITRO DISSOLUTION AND ORAL BIOAVAILABILITY IN RABBIT
}

\author{
SUVENDU KUMAR SAHO0 ${ }^{1 *}$, PADILAM SURESH ${ }^{2}$, USHARANI ACHARYA ${ }^{3}$
}

${ }^{1}$ GITAM Institute of Pharmacy, GITAM Deemed to be University, Visakhapatnam, Andhra Pradesh, India, ${ }^{2}$ School of Pharmacy, Guru Nanak Institutions Technical Campus, Hyderabad, Telangana, India, ${ }^{3}$ Department of Zoology, Berhampur University, Berhampur, Odisha, India Email: suvendu.gip@gmail.com

Received: 30 Apr 2018, Revised and Accepted: 24 May 2018

\section{ABSTRACT}

Objective: The main purpose of this investigation was to prepare self-microemulsifying drug delivery system (SMEDDS) for enhancement of oral bioavailability of a poorly water soluble drug telmisartan (TLS), a BCS class II drug by improving its dissolution rate.

Methods: Self-Emulsifying Drug Delivery Systems (SEDDS) of TLS were formulated using cinnamon essential oil as the oil phase, Gelucire 44/14 as the surfactant and Transcutol HP as co-surfactant. Drug-excipient interactions were studied by FTIR spectroscopy. The formulations were evaluated for its self-emulsifying ability, clarity, and stability of the aqueous dispersion after $48 \mathrm{~h}$ and the phase diagram was constructed to optimize the system. Selected formulations were characterized in terms of droplet size distribution, zeta potential, cloud point and were subjected to in vitro drug release studies. The bioavailability of optimized formulation was assessed in New Zealand white rabbits.

Results: By considering smaller droplet size, higher zeta potential and faster rate of drug release the formulation TF9 was chosen as optimized SMEDDS formulations. TF9 was robust to different $\mathrm{pH}$ media and dilution volumes, remained stable after three cooling-heating cycles and after stored at $4{ }^{\circ} \mathrm{C}$ and $25^{\circ} \mathrm{C}$ for 3 mo without showing a significant change in droplet size. The pharmacokinetic study in rabbits showed SMEDDS have significantly increased the $\mathrm{C}_{\max }$ and area under the curve (AUC) of TLS compared to suspension $(\mathrm{P}<0.05)$.

Conclusion: SMEDDS can be an effective oral dosage form for enhancing aqueous solubility and improving oral bioavailability of poorly water soluble drugs.

Keywords: Telmisartan, SMEDDS, Cinnamon essential oil, Gelucire 44/14, Transcutol HP, aqueous solubility, dissolution rate, bioavailability

(C) 2018 The Authors. Published by Innovare Academic Sciences Pvt Ltd. This is an open access article under the CC BY license (http://creativecommons.org/licenses/by/4.0/)

DOI: http://dx.doi.org/10.22159/ijap.2018v10i4.27048

\section{INTRODUCTION}

The oral route of drug administration has always been preferred due to its simplicity, patient convenience, compliance, accurate dosage and low cost of production [1]. A most essential requirement for oral absorption is that the drug must present in a solubilized state prior to passage across the gastrointestinal (GI) membrane. There are various pharmaceutical and physiological factors which affect the gastrointestinal absorption as well as the bioavailability of the drugs [2]. The reasons which contributed to poor oral bioavailability include less aqueous solubility, inadequate lipophilicity, and gastrointestinal degradation of the drug, presystemic metabolism and P-glycoprotein (Pgp) efflux of some drugs [3, 4]. Though continuous attempts are undertaken to minimize the solubility problems, approximately $40 \%$ of the currently marketed immediaterelease (IR) oral drugs [5] and up to 75\% of compounds currently under development have been categorized to be poorly water soluble $(<100 \mu \mathrm{g} / \mathrm{ml})[6,7]$. These low soluble drugs exhibit poor bioavailability where dissolution is the rate-limiting step [8]. The various strategies such as solid dispersions [9], complexation with cyclodextrin [10], micronization, nanoparticles, permeation enhancers [11], cocrystal formation [12] and lipid-based formulations [13] have been reported in the literature. In recent years much attention has been focused on lipid-based formulations [14] with emphasis on self-emulsifying drug delivery systems (SEDDS) to improve oral bioavailability of lipophilic drugs [15]. Self-micro emulsifying drug delivery systems (SMEDDS) are defined as the isotropic mixtures of oil, surface active agents and co-surfactant (CoS) in which a particular drug is present in the dissolved state and such system rapidly form fine oil-in-water (o/w) microemulsions when introduced into the aqueous medium under mild agitation [16]

Telmisartan, a BCS class II drug [17] is widely used in the treatment of hypertension. The drug is practically insoluble in water and shows dissolution rate limited bioavailability. Therefore the aim of present study was to improve the oral bioavailability of TLS via SMEDDS approach.

The conventional SMEDDS include a relatively large amount of surfactants (>70\%), which may induce GI irritation and side-effects [18]. In order to achieve a safe and efficient delivery system for the poor oral bioavailability drugs, the investigation was aimed to design a novel SMEDDS with a high proportion of cinnamon oil (an essential oil as the carrier for lipophilic drugs).

The aim of the present investigation was to develop and characterize the optimized formulation of SMEDDS containing telmisartan and to assess its bioavailability in the rabbits.

In the present investigation, essential oil was used to replace part of the surfactant for reducing the potential toxicity of the formulation. It was observed that high essential oil containing SMEDDS formulations possess excellent self-emulsifying property, stability and suitable in vitro drug release profile, without affecting the drug loading capacity.

Studies on mean particle sizes of microemulsions were conducted by dynamic light scattering (DLS) technique. The in vitro release profiles of telmisartan from SMEDDS and the prepared TLS suspension were compared. Various pharmacokinetics parameters were investigated for optimized SMEDDS and prepared TLS suspension and relative oral bioavailability of TLS was assessed.

\section{MATERIALS AND METHODS}

\section{Materials}

Telmisartan was received as a gift sample from Dr. Reddy's Laboratory (Hyderabad, India). Gelucire 44/14 (Lauroyl Polyoxyl-32 glycerides) and Transcutol HP (Diethylene glycol monoethyl ether) were kindly provided by Gattefosse India Pvt. Ltd. (Mumbai). Anise oil, cinnamon oil, and lemon essential oil were purchased from 
Genuine Chemicals Co. (Mumbai, India). Oleic acid ((9Z)-Octadec-9enoic acid), polyethylene glycol 400 and propylene glycol were purchased from Molychem (Mumbai, India). Tween (R) 80 (Polyoxyethylene (20) sorbitan monooleate) and olive oil were purchased from Loba Chemie Pvt. Ltd. (Mumbai, India). Glycerol was purchased from Sisco Research Laboratory (Mumbai, India), Cremophore RH40 and dialysis membrane (DM-50) were purchased from Himedia (Mumbai, India). All the excipients and reagents were of analytical grade and double distilled water was freshly prepared whenever required throughout the study. For the pharmacokinetic study, New Zealand white rabbits were obtained from Sanzyme Bioanalytical Laboratory, Hyderabad (Regd. No.:1837/PO/RcBT/ S/15/CPCSEA).

\section{Methods}

\section{Solubility study}

Solubility studies for the drug in different vehicles were carried by placing an excess amount of telmisartan in screw-capped vials containing $2 \mathrm{ml}$ of vehicle. To facilitate the solubilization, the suspensions were heated on a water bath at $40{ }^{\circ} \mathrm{C}$ and then stirred using vortex mixer. The suspensions were continuously agitated on a water bath shaker for $48 \mathrm{~h}$ at ambient temperature until equilibrium was reached. Then the samples were centrifuged at $3000 \mathrm{rpm}$ for 15 min and the supernatant was taken, filtered through the membrane filter $(0.45 \mu \mathrm{m}, 13 \mathrm{~mm}$, Whatman, USA). The filtrates were suitably diluted with methanol and analyzed by UV-Visible spectrophotometer (Shimadzu, Japan) for the dissolved drug at $294 \mathrm{~nm}$ [19].

\section{Surfactant and oil miscibility}

The oil and surfactant in the ratio of $1: 1$ were shaken at $40{ }^{\circ} \mathrm{C}$ in $5 \mathrm{ml}$ transparent glass vials. The miscibility was monitored optically and considered to be good when the mixture was transparent.

\section{Fourier transform infrared spectroscopy}

To investigate any possible interaction between the drug and utilized excipients, FTIR spectroscopy was used [20]. The IR spectra of pure drug and that of SEDDS were recorded by using FTIR Spectrometer (FTIR-8400S, Shimadzu, Japan). Sample preparation includes mixing a small quantity of the sample with Nujol and was placed in the FTIR sample holder. The IR spectrum was recorded from regions of $4000 \mathrm{~cm}^{-1}$ to $400 \mathrm{~cm}^{-1}$.

\section{Preparation of SEDDS}

A series of SEDDS formulations were prepared with varying ratios of oil (30-70\%), surfactant (20-69\%) and co-surfactant (4-27\%) as shown in table 1 . The surfactant and co-surfactant $(\mathrm{S} / \mathrm{CoS})$ were used at the ratio of 2:1, 4:1 and 6:1. A single dose of TLS $(20 \mathrm{mg} / \mathrm{ml})$ was incorporated in all formulations. The formulations were developed by dissolving the drug in oil followed by addition of surfactant previously heated to $50^{\circ} \mathrm{C}$ and co-surfactant in glass vials. The resultant mixtures were stirred continuously by vortex mixing and heated at $50{ }^{\circ} \mathrm{C}$ to obtain a homogeneous isotropic mixture. The SEDDS formulations were stored at ambient temperature until further use.

Table 1: Composition of SEDDS formulations of telmisartan ( $\% \mathrm{v} / \mathrm{v})$

\begin{tabular}{|c|c|c|c|}
\hline \multirow[t]{2}{*}{ Formulation } & \multicolumn{3}{|c|}{ Ingredients (\% v/v) } \\
\hline & Cinnamon oil & Gelucire 44/14 & Transcutol HP \\
\hline TF1 & 20 & 53.3 & 26.6 \\
\hline TF2 & 20 & 64 & 16 \\
\hline TF3 & 20 & 68.5 & 11.4 \\
\hline $\mathrm{TF} 4$ & 30 & 46.6 & 23.3 \\
\hline TF5 & 30 & 56 & 14 \\
\hline TF6 & 30 & 60 & 10 \\
\hline TF7 & 40 & 40 & 20 \\
\hline TF8 & 40 & 48 & 12 \\
\hline TF9 & 40 & 51.4 & 8.5 \\
\hline TF10 & 50 & 33.3 & 16.6 \\
\hline TF11 & 50 & 40 & 10 \\
\hline TF12 & 50 & 42.6 & 7.4 \\
\hline TF13 & 60 & 26.6 & 13.4 \\
\hline TF14 & 60 & 32 & 8 \\
\hline TF15 & 60 & 34.3 & 5.7 \\
\hline TF16 & 70 & 20 & 10 \\
\hline TF17 & 70 & 24 & 6 \\
\hline TF18 & 70 & 25.7 & 4.3 \\
\hline
\end{tabular}

\section{Construction of ternary phase diagrams}

Ternary phase diagrams of the selected oils, surfactants and cosurfactants at various proportions were constructed to identify the self-emulsification regions. All the formulations were investigated with various proportions of oil, surfactant and co-surfactant for each system. All the formulations were observed visually immediately for spontaneity of emulsification, clarity, phase separation and precipitation of drug and excipients [21]. Briefly, $0.5 \mathrm{ml}$ formulations were added drop by drop to $500 \mathrm{ml}$ enzyme-free simulated gastric fluid (SGF pH 1.2) at $37.0 \pm 0.5^{\circ} \mathrm{C}$; the mixtures were gently stirred on a magnetic stirrer at $100 \mathrm{rpm}$ to simulate the gastrointestinal wriggle. The resultant emulsions were stored for $48 \mathrm{~h}$ at ambient temperature and observed for clarity, coalescence of droplets, phase separation and drug precipitation. Emulsions showing phase separation, cracking and coalescence of oil droplets were judged as unstable emulsions. All the studies were repeated three times with and without drug with similar observations made between repeats. The mixtures were considered well dispersed when the formulation spread quickly in SGF and was clear or milk-white color with no phase separation or coalescence after the stirring stopped. Phase diagram was constructed identifying the self-emulsifying region using ProSim Ternary Diagram software.

\section{Characterization of SEDDS}

\section{Visual assessment of self-emulsification time and appearance}

Assessment of the self-emulsifying properties of SEDDS formulations was performed by visual observation. The USP type II dissolution apparatus (Electrolab, Mumbai, India) was used to assess the efficiency of self-emulsification of different formulations. $1 \mathrm{~g}$ of each formulation was added dropwise into $500 \mathrm{ml}$ of distilled water maintained at $37^{\circ} \mathrm{C}$ with gentle agitation condition provided by rotating paddle at $50 \mathrm{rpm}$. Begin timing after the formulation was added completely and stop until the homogeneous emulsion was formulated. The appearance of emulsions was monitored and categorized as clear, translucent and cloudy. The in vitro performances of the formulations were visually assessed using the grading system as discussed by Khoo et al. [22].

\section{Droplet size and zeta (Ъ)-potential measurements}

The mean droplet size ( $\mathrm{z}$ average), polydispersity index (PDI) and $\zeta$ potential of stable formulations were determined at $25{ }^{\circ} \mathrm{C}$ with a 
Zetasizer Nano-ZS dynamic light scattering apparatus (Malvern Instruments, UK). Each formulation was diluted with filtered $(0.45$ $\mu \mathrm{m}$, Millipore) double distilled water before analysis. Size analysis was carried at $25^{\circ} \mathrm{C}$ with an angle of detection of $90^{\circ}$.

\section{Effect of $\mathrm{pH}$ and robustness to dilution}

Formulations were subjected to 50,100,1000 and 3000 fold dilution with enzyme-free SGF ( $\mathrm{pH} \mathrm{1.2),} \mathrm{enzyme-free} \mathrm{simulated} \mathrm{intestinal}$ fluid (SIF, pH 6.8) and distilled water. The resultant diluted emulsions were observed for any physical changes such as (coalescence of droplets, phase separation or precipitation of drugs) after $24 \mathrm{~h}$ storage [23].

\section{Formulation stability}

Selected TLS-loaded formulations underwent three consecutive cooling and heating cycle to assess their stability [24]. Each cycle consisted of cooling the formulation at $4{ }^{\circ} \mathrm{C}$ for $24 \mathrm{~h}$ in the refrigerator, followed by heating at $45{ }^{\circ} \mathrm{C}$ for $48 \mathrm{~h}$ in an incubator. The droplet size, PDI, and $\zeta$-potential of the emulsions were determined after each cycle, and moreover every month on formulations stored at $4{ }^{\circ} \mathrm{C}$ and $25^{\circ} \mathrm{C}$ for up to three months.

\section{Cloud point measurement}

The cloud point measurement was carried out for the stable formulations. The formulation was diluted 100 times with distilled water and kept in a water bath which was maintained at a temperature of $25{ }^{\circ} \mathrm{C}$ with a gradual increase of temperature at a rate of $5{ }^{\circ} \mathrm{C} / \mathrm{min}$ and the corresponding cloud point temperatures were read at first sign of turbidity by visual observation [25].

\section{In vitro drug release studies}

Drug release experiments were conducted using a modified dialysis method [26]. Initially, the dialysis membrane tubing was soaked in the release medium for $12 \mathrm{~h}$ at room temperature which was treated at $40{ }^{\circ} \mathrm{C}$ before the start of the experiment. The diluted SMEDDS formulation (equivalent to $20 \mathrm{mg}$ TLS) and $1 \mathrm{ml}$ TLS suspension (20 $\mathrm{mg}$ TLS in SGF pH 1.2 as the control) were placed in dialysis tubing and clamped on both sides. The secured dialysis tube was tied to the paddle of the apparatus and allowed to rotate freely in the dissolution vessel of USP type-II dissolution apparatus (Electrolab Dissolution Tester (USP) TDT-06L, Mumbai, India) containing 500 $\mathrm{ml}$ of enzyme-free $\mathrm{SGF}(\mathrm{pH} 1.2)$ at $37 \pm 0.5^{\circ} \mathrm{C}$ and stirred at $50 \mathrm{rpm}$. An aliquot of $5 \mathrm{ml}$ was withdrawn at predetermined time intervals $(15,30,45,60,75,90,120,150180$ and $240 \mathrm{~min})$ and filtered through $0.45 \mu$ filter. The withdrawn volume was replenished immediately with the same volume of fresh medium in order to keep total volume constant and maintain sink conditions. The concentration of TLS in the filtrate was analyzed using UV spectrophotometer at $294 \mathrm{~nm}$. The blank SEDDS without drug was carried out similarly and used as a reference to circumvent interference from the formulation components if any. The mean of at least three determinations was used to calculate the drug release.

\section{Pharmacokinetic studies}

In vivo studies were carried out as per the guidelines of the Institutional Animal Ethics Committee (Regd. No. IAEC/GIP1287/SKS-F/Approved/10/2017-18). New Zealand white rabbits $(1.8-2.0 \mathrm{~kg})$ of either sex were housed under standard conditions of temperature, relative humidity, and light. Unless otherwise specified, food and water were given ad libitum.

All animals were separated into two groups [Group-I and Group-II], with 6 animals in each group and fasted for $24 \mathrm{~h}$. The TLS $(1 \mathrm{mg} / \mathrm{kg})$ pure drug in aqueous suspension in $0.5 \%$ sodium carboxymethyl cellulose for Group-I animals and optimized SMEDDS formulation (equivalent to $1 \mathrm{mg} / \mathrm{kg}$ TLS) for Group-II animals were administered orally with the help of oral feeding needle. Water was given ad libitum during fasting and throughout the experiment.

After drug administration, $1 \mathrm{ml}$ of blood sample was collected from marginal ear vein at time intervals of $0,0.5,1,1.5,2,3,4$ and $6 \mathrm{~h}$ in the precoated EDTA tubes. The samples were centrifuged at 3000 rpm for $15 \mathrm{~min}$ and the separated plasma samples were stored at refrigerated conditions $\left(2-8^{\circ} \mathrm{C}\right)$ until analysis. Telmisartan contents of the plasma samples were determined by HPLC method.

\section{Estimation of pharmacokinetic parameters}

The pharmacokinetic parameters for the drug in control and optimized SEDD formulation following oral administration were determined from plasma concentration data. Various pharmacokinetic parameters such as peak plasma concentration $\left(\mathrm{C}_{\max }\right)$, time of peak plasma concentration $\left(t_{\max }\right)$, the area under the curve (AUC) were calculated in each case using the data. The total area under the concentration-time curve (AUC) from time zero to $8 \mathrm{~h}$ were be calculated by the trapezoidal rule method. The maximal concentration $\left(\mathrm{C}_{\max }\right)$ and the time to maximal concentration $\left(\mathrm{t}_{\max }\right)$ were obtained directly by observation. The relative bioavailability (BA) of SMEDDS form to the control was calculated using the following equation.

$$
\% \text { Relative B. A. }=\frac{\mathrm{AUC}_{\text {test }}}{\mathrm{AUC}_{\text {Reference }}} \times \frac{\text { Dose }_{\text {reference }}}{\text { Dose }_{\text {test }}} \times 100
$$

The pharmacokinetic parameters were performed by noncompartmental analysis. All values are expressed as the mean \pm SD

\section{Statistical treatment of the data}

The pharmacokinetic data of TF9 SMEDDS and reference formulations were compared by the Student's t-test. A p-value of less than 0.05 was considered as statistically significant.

\section{RESULTS}

\section{Solubility studies}

The drug-loading capacity of the SEDDS formulations depends on the solubility of TLS in the various vehicles of the system, which was determined by solubility studies. The results are presented in fig. 1 .

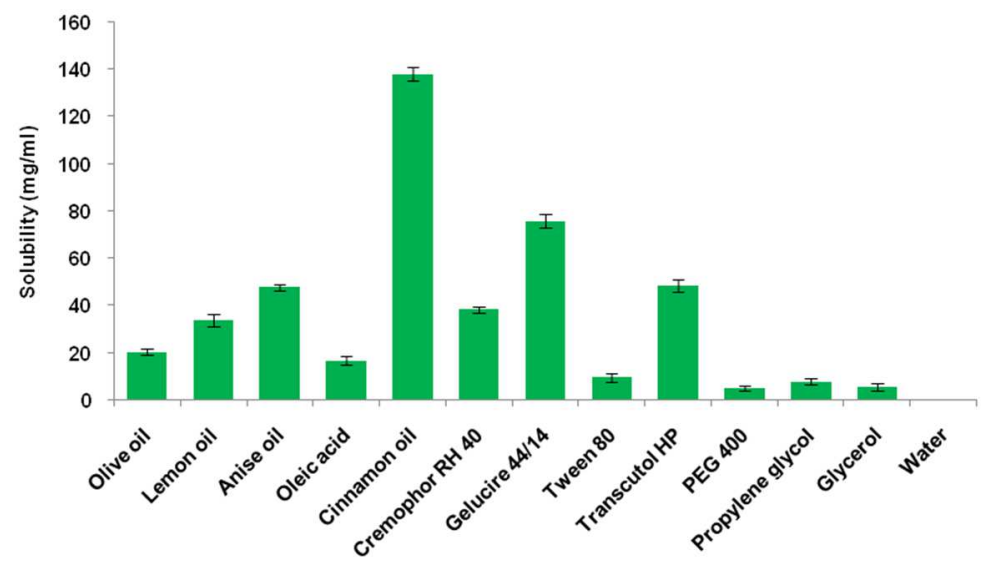

Fig. 1: Solubility of telmisartan in various vehicles; each value is expressed as mean $\pm \operatorname{SD}(n=3)$ 
FTIR study

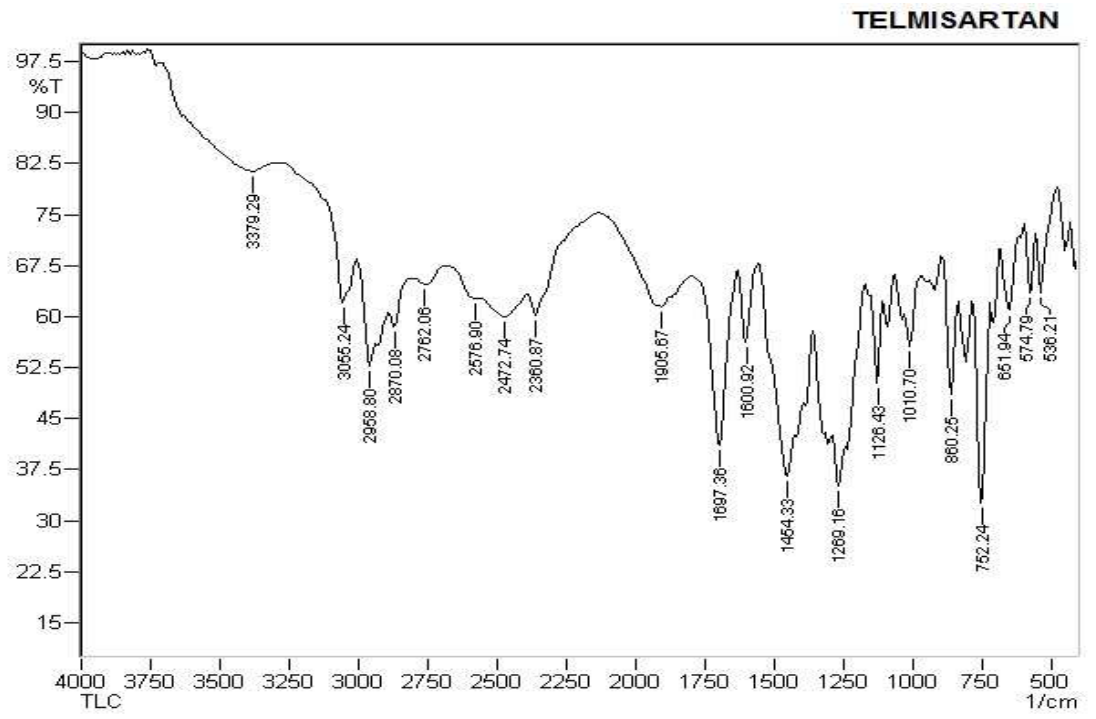

Fig. 2: FTIR spectrum of telmisartan

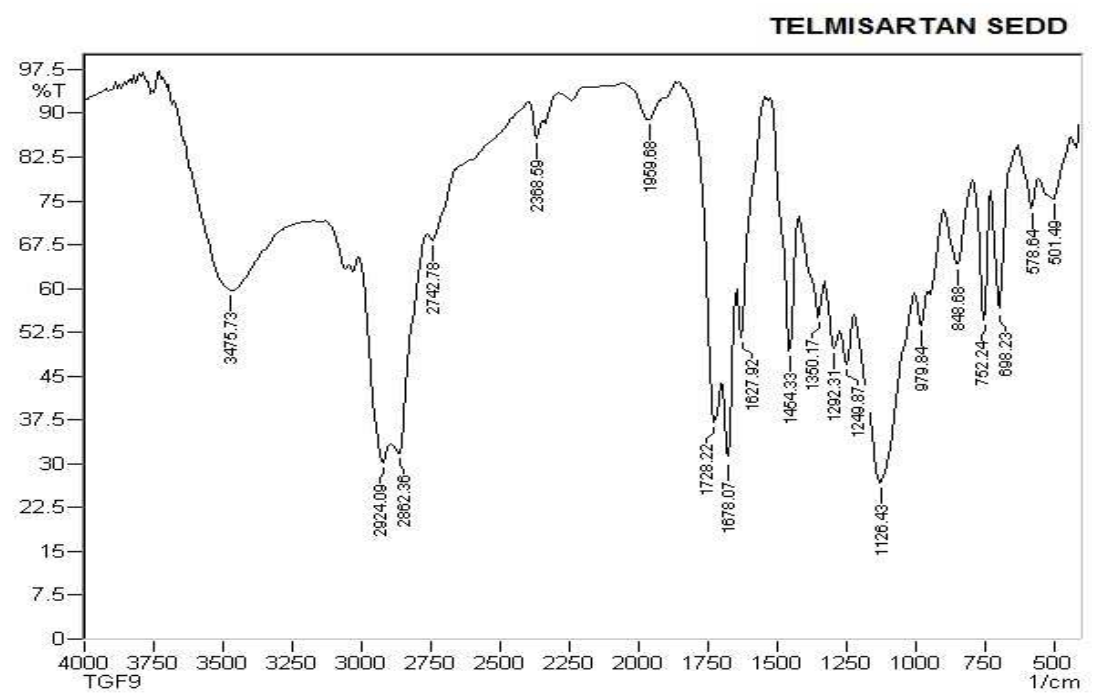

Fig. 3: FTIR spectrum of SEDDS (TF9)

\section{Ternary phase diagram}

A ternary phase diagram was investigated for the prepared formulations. Before the construction of ternary phase diagrams, the miscibility between surfactants and oils was investigated to select the best components. The mixture of surfactant Gelucire 44/14 and cinnamon essential oil resulted in clear solutions. Formation of emulsion systems (the green area in fig. 4) was observed at ambient temperature.

\section{Self-emulsification efficiency and appearance}

The efficiency of self-emulsification could be estimated by determining the rate of emulsification. The results of rate of emulsification are shown in table 2 . The results suggested that all the formulations except TF7 and TF8, up to $40 \%$ oil content showed the emulsification time of less than $60 \mathrm{sec}$.

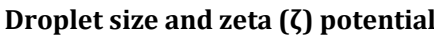

Droplet size, PDI and $\zeta$-potential of the optimized SEDDS in SGF with $(20 \mathrm{mg} / \mathrm{ml})$ and without TLS are listed in table 3.

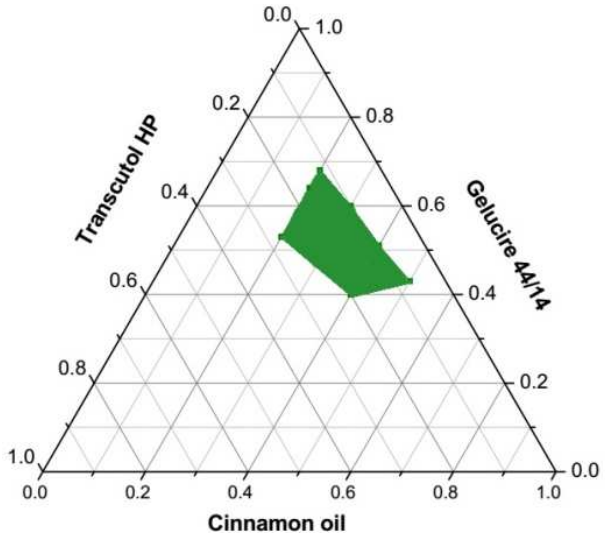

Fig. 4: Ternary phase diagram of SEDDS between cinnamon oil, gelucire 44/14 and transcutol HP (green domain indicates the region of self emulsification 
Table 2: Evaluation parameters of telmisartan loaded SEDDS formulations

\begin{tabular}{llll}
\hline Formulation & Self-emulsification time* [Sec] & Clarity* & Stability after 48 h* \\
\hline TF1 & $32 \pm 3$ & Translucent & Unstable \\
TF2 & $24 \pm 1$ & Transparent & Stable \\
TF3 & $21 \pm 2$ & Transparent & Stable \\
TF4 & $42 \pm 4$ & Translucent & Unstable \\
TF5 & $34 \pm 2$ & Translucent & Stable \\
TF6 & $30 \pm 3$ & Transparent & Stable \\
TF7 & $103 \pm 4$ & Cloudy & Unstable \\
TF8 & $82 \pm 3$ & Translucent & Stable \\
TF9 & $54 \pm 2$ & Translucent & Stable \\
TF10 & $142 \pm 4$ & Cloudy & Unstable \\
TF11 & $119 \pm 3$ & Cloudy & Unstable \\
TF12 & $112 \pm 2$ & Translucent & Unstable \\
TF13 & $171 \pm 4$ & Cloudy & Unstable \\
TF14 & $138 \pm 4$ & Cloudy & Unstable \\
TF15 & $125 \pm 3$ & Cloudy & Unstable \\
TF16 & $208 \pm 4$ & Cloudy & Bnstable \\
TF17 & $184 \pm 6$ & Cloudy & Unstable \\
TF18 & $162 \pm 5$ & Cloudy & C \\
\hline
\end{tabular}

${ }^{*}$ Data expressed as mean \pm SD $(n=3)$

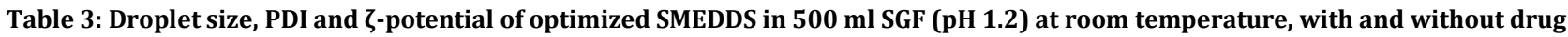

\begin{tabular}{|c|c|c|c|c|c|c|}
\hline \multirow[t]{2}{*}{ Formulation } & \multicolumn{3}{|l|}{ Without drug } & \multicolumn{3}{|c|}{ With drug $(20 \mathrm{mg} / \mathrm{ml})$} \\
\hline & Droplet size* [nm] & PDI & Zeta potential* [mV] & Droplet size* [nm] & PDI & Zeta potential* $[\mathrm{mV}]$ \\
\hline TF2 & $201.98 \pm 9.24$ & 0.192 & $-7.39 \pm 2.61$ & $236.58 \pm 10.37$ & 0.205 & $-7.53 \pm 2.91$ \\
\hline TF3 & $187.65 \pm 8.18$ & 0.201 & $-7.25 \pm 2.86$ & $205.26 \pm 9.61$ & 0.227 & $-7.59 \pm 2.72$ \\
\hline TF5 & $198.54 \pm 6.77$ & 0.192 & $-5.53 \pm 2.29$ & $213.82 \pm 5.96$ & 0.186 & $-6.04 \pm 2.15$ \\
\hline TF6 & $135.52 \pm 7.31$ & 0.283 & $-8.26 \pm 2.41$ & $161.14 \pm 8.48$ & 0.276 & $-8.37 \pm 2.84$ \\
\hline TF8 & $179.37 \pm 9.46$ & 0.289 & $-7.01 \pm 2.35$ & $197.65 \pm 7.29$ & 0.315 & $-6.57 \pm 2.38$ \\
\hline TF9 & $134.85 \pm 3.55$ & 0.275 & $-4.52 \pm 0.72$ & $150.72 \pm 3.64$ & 0.290 & $-4.58 \pm 0.96$ \\
\hline TF12 & $262.46 \pm 7.39$ & 0.316 & $-4.95 \pm 1.52$ & $278.37 \pm 6.18$ & 0.328 & $-5.75 \pm 1.43$ \\
\hline
\end{tabular}

${ }^{*}$ Data expressed as mean \pm SD $(n=3)$

Results

Size (d.nm): $\quad \%$ Intensity: $\quad$ St Dev (d.n...

Z-Average (d.nm): 149.6

Pdl: 0.290

Intercept: 0.965

Result quality: Good

$\begin{array}{llll} & \text { Size (d.nm): } & \% \text { Intensity: } & \text { St Dev (d.n... } \\ \text { Peak 1: } & 207.1 & 100.0 & 120.0 \\ \text { Peak 2: } & 0.000 & 0.0 & 0.000 \\ \text { Peak 3: } & 0.000 & 0.0 & 0.000\end{array}$

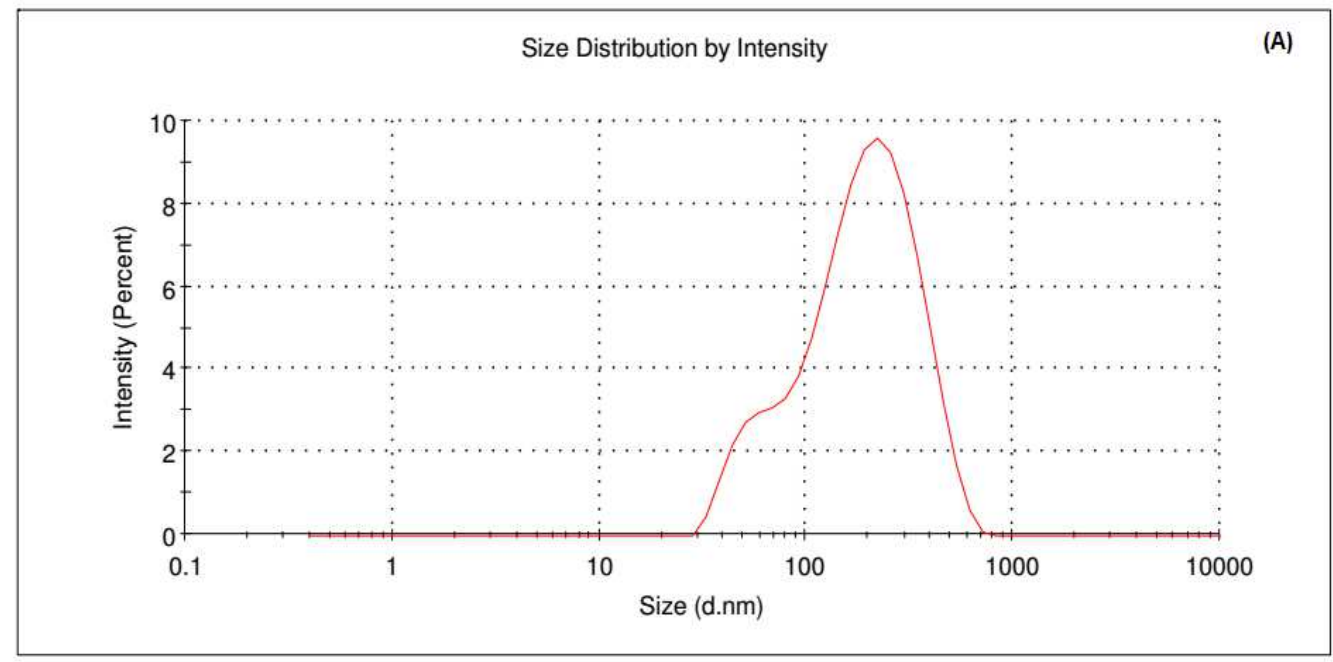

Fig. 5: Droplet size distribution of telmisartan-loaded microemulsion (TF9) 


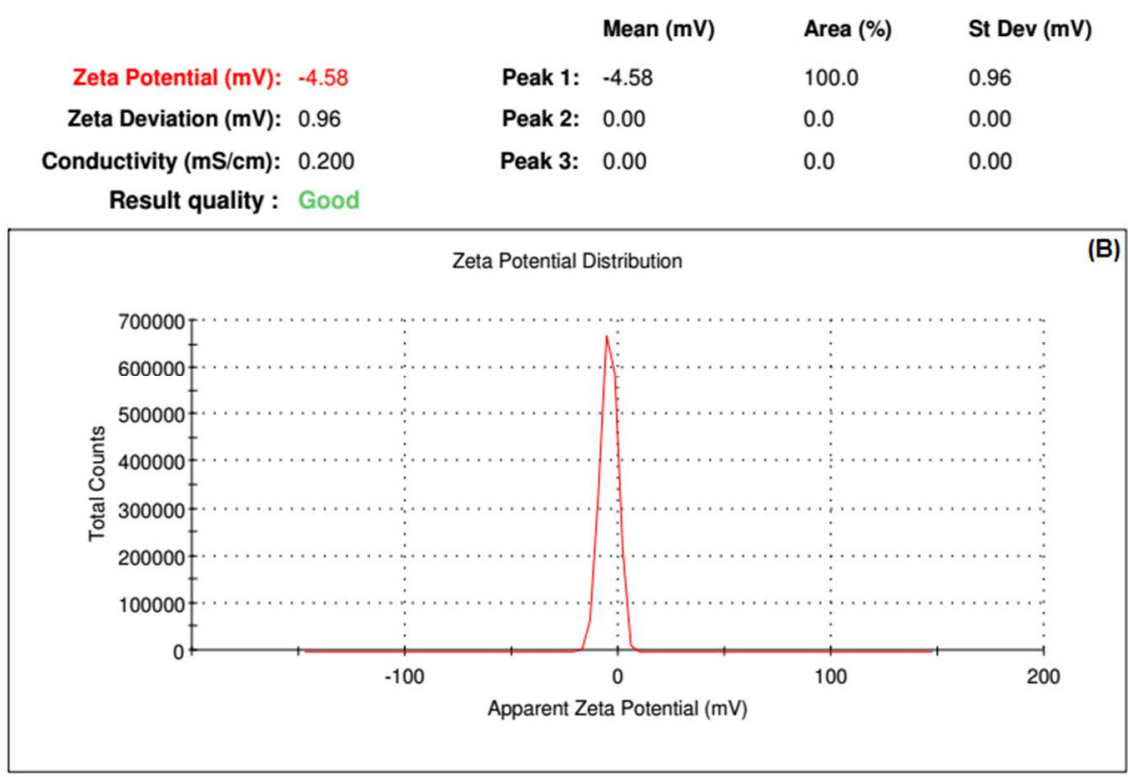

Fig. 6: Zeta potential of telmisartan-loaded microemulsion (TF9)

Effect of $\mathrm{pH}$ and robustness to dilution
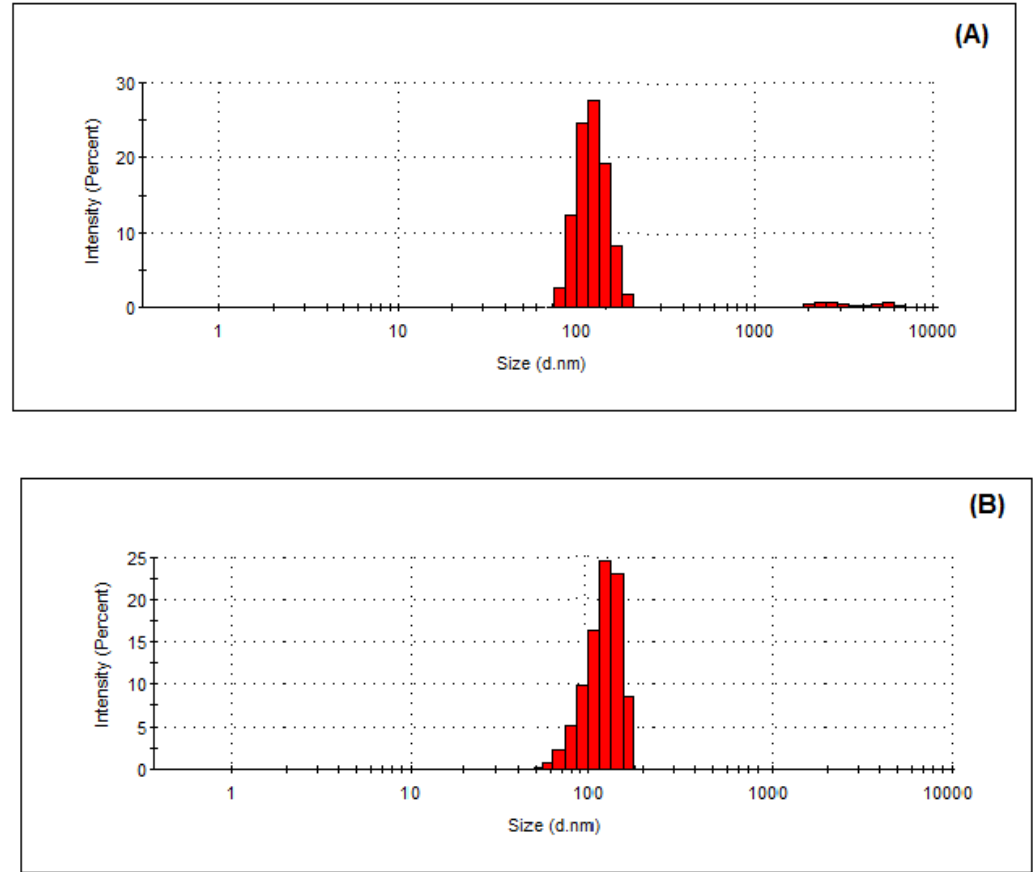

(B)

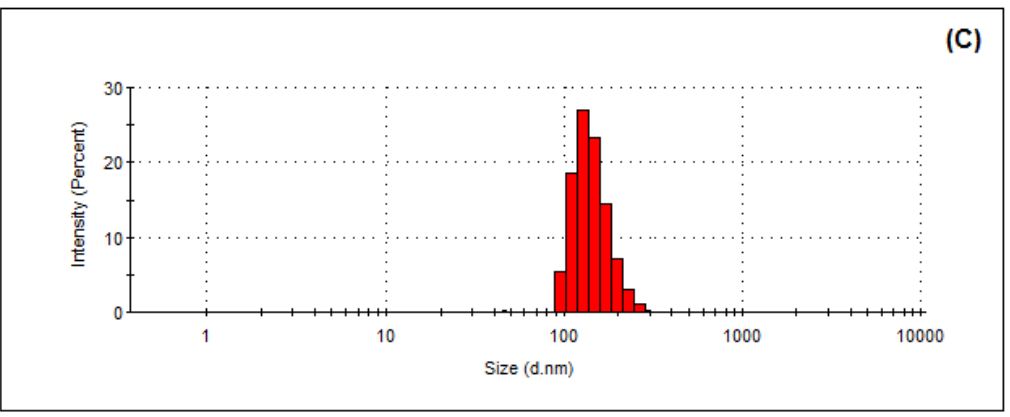

Fig. 7: Particle size distributions of the micro emulsions generated from Formulation TF9 in (A): enzyme free simulated gastric fluid (pH 1.2), (B): enzyme free simulated intestinal fluid ( $\mathrm{pH} 6.8$ ) and (C): distilled water 
Table 4: Effects of cooling and heating cycles on the dynamic characteristics of micro emulsions obtained from TF9 containing $20 \mathrm{mg} / \mathrm{ml}$ Telmisartan in enzyme free SGF $(\mathrm{pH} 1.2,500 \mathrm{ml})$

\begin{tabular}{llll}
\hline Cooling $\left(\mathbf{4}^{\circ} \mathbf{C}\right)$ and heating $\left(\mathbf{4 5}^{\circ} \mathbf{C}\right)$ cycle & Droplet size ${ }^{*}[\mathbf{n m}]$ & PDI & Zeta potential $^{*}[\mathbf{m V}]$ \\
\hline-- & $150.72 \pm 3.64$ & 0.290 & $-4.82 \pm 0.96$ \\
First & $154.68 \pm 2.85$ & 0.293 & $-4.81 \pm 0.85$ \\
Second & $155.29 \pm 4.38$ & 0.305 & $-4.79 \pm 0.99$ \\
Third & $157.16 \pm 3.47$ & 0.287 & $-4.83 \pm 0.91$ \\
\hline
\end{tabular}

${ }^{*}$ Data expressed as mean $\pm \mathrm{SD}(\mathrm{n}=3)$

Table 5: Effects of storage conditions on the dynamic characteristics of microemulsion obtained from TF9 containing $20 \mathrm{mg} / \mathrm{ml}$ Telmisartan in enzyme free SGF (pH 1.2, $500 \mathrm{ml})$

\begin{tabular}{llll}
\hline $\begin{array}{l}\text { Storage Time } \\
\text { (months) }\end{array}$ & Temperature, $\mathbf{4}^{\circ} \mathbf{C}$ & \multicolumn{1}{c}{ Temperature, 25 $^{\circ} \mathbf{C}$} \\
\cline { 2 - 4 } & Droplet size* $[\mathbf{n m}]$ & PDI & Droplet size* [nm] \\
\hline 1 & $150.36 \pm 5.86$ & 0.214 & $151.45 \pm 4.39$ \\
3 & $150.87 \pm 6.69$ & 0.371 & $152.92 \pm 7.72$ \\
\hline
\end{tabular}

${ }^{*}$ Data expressed as mean $\pm \operatorname{SD}(n=3)$

\section{Formulation stability}

The stability of TF9, after three cooling and heating cycles, is summarized in table 4 and the effect of storage conditions on the microemulsion stability is presented in table 5 .

\section{Cloud point measurement}

The cloud point is the temperature above which the clarity of formulation turns to cloudiness. This is due to drug precipitation and phase separation of the emulsion. Since both the drug solubilization and stability of emulsion decreases with phase separation, cloud point should be preferably above $37^{\circ} \mathrm{C}$.

The cloud point temperatures of different formulations determined were in the range of $62-76^{\circ} \mathrm{C}$.

\section{In vitro drug release study}

To facilitate the real drug release pattern the dialysis bag method was utilized in drug release studies and the drug release pattern of SMEDDS shown in fig. 8 .

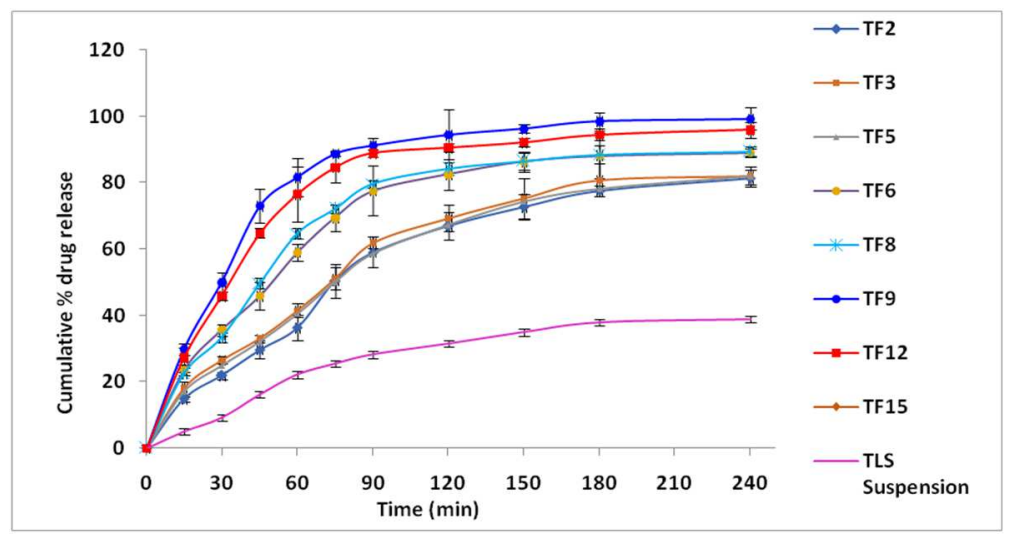

Fig. 8: In vitro release profile of Telmisartan suspension and Telmisartan-SMEDDS (Emulsified with SGF, pH = 1.2, $10 \mathrm{ml})$ in SGF (pH = 1.2, $500 \mathrm{ml})$. Data expressed as mean $\pm \mathrm{SD}(\mathrm{n}=6)$

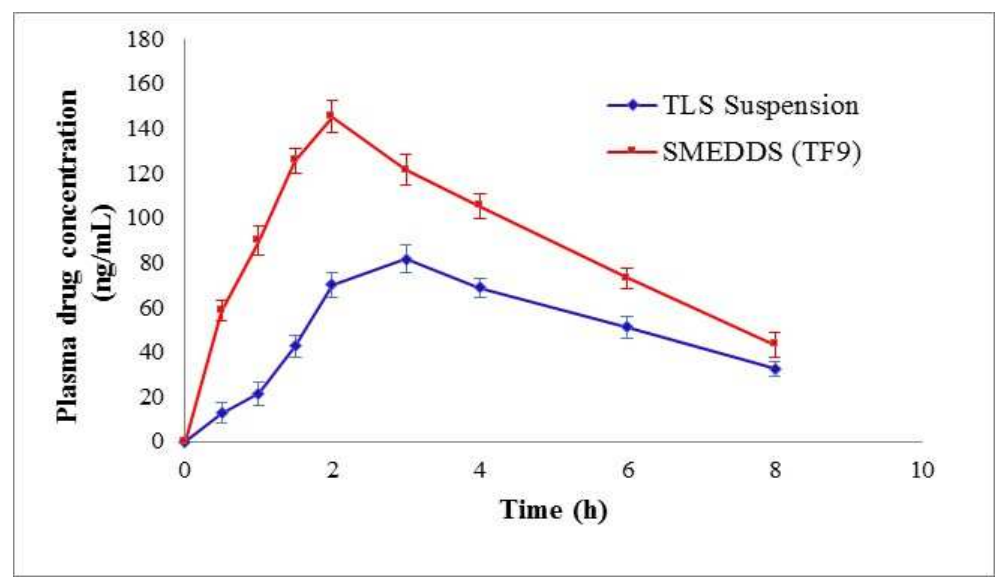

Fig. 9: Plasma concentration of telmisartan after oral administration of TLS suspension and SMEDDS (TF9) to rabbits. Data expressed as mean $\pm \operatorname{SD}(n=6)$ 
Table 6: Pharmacokinetic parameters of Telmisartan after oral administration of TLS suspension and SMEDDS (TF9) in rabbits

\begin{tabular}{lll}
\hline Parameters* & TLS suspension & SMEDDS \\
\hline $\mathrm{C}_{\max }(\mu \mathrm{g} / \mathrm{ml})$ & $81.62 \pm 5.99$ & $145.28 \pm 7.34$ \\
$\mathrm{t}_{\max }(\mathrm{h})$ & $3.00 \pm 0.00$ & $2.00 \pm 0.00$ \\
$\mathrm{AUC}_{(0-8) \mathrm{h}}(\mu \mathrm{g} \mathrm{h} / \mathrm{ml})$ & $425.48 \pm 11.35$ & $1013.21 \pm 15.42$ \\
Relative bioavailability $(\%)$ & -- & 238.15 \\
\hline
\end{tabular}

Each value expressed as mean \pm SD $(n=6)$., ${ }^{*} \mathrm{P}<0.05$ by the Student t-test.

\section{Pharmacokinetic studies}

The plasma concentration versus time profiles of TLS in rabbits for SMEDDS and TLS suspension following oral administration are presented in fig. 9. The pharmacokinetic parameters of TLS were computed and tabulated in table 6 .

\section{DISCUSSION}

Among the five oils those have been tested, TLS is highly soluble in cinnamon essential oil (about $138.09 \pm 2.82 \mathrm{mg} / \mathrm{ml}$ ) which is better than anise oil $(47.92 \pm 1.32 \mathrm{mg} / \mathrm{ml})$, lemon essential oil $(34 \pm 2.66$ $\mathrm{mg} / \mathrm{ml})$, olive oil $(20.59 \pm 1.09 \mathrm{mg} / \mathrm{ml})$ and oleic acid $(16.78 \pm 1.78$ $\mathrm{mg} / \mathrm{ml}$ ). The surfactant has a pivotal role in stabilizing microemulsions, its nature and amount determining droplet size and stability [27]. Nonionic surfactants are usually preferred because of their lower toxicity and higher stability to the effect of $\mathrm{pH}$ and ionic strength than ionic and amphiphilic surfactants [28]. The hydrophilic-lipophilic balance (HLB) is a measure of the degree to which a substance is hydrophilic or lipophilic [29]. An HLB value of 20 defines a fully hydrophilic molecule, while a value of 0 defines a lipophilic one [30]. The stability of emulsions depends also on the ratio between the high HLB and low HLB surfactant amounts [21,31]. As shown in fig. 1, among all the investigated surfactants, TLS exhibited quite higher solubility in Gelucire 44/14 (HLB 14) $76.02 \pm 2.79 \mathrm{mg} / \mathrm{ml}$ than Cremophor RH40 (HLB 15), $38.5 \pm 1.45$ $\mathrm{mg} / \mathrm{ml}$; Tween 80 (HLB 15), $9.75 \pm 1.68 \mathrm{mg} / \mathrm{ml}$; and the former was selected for further investigations. The solubility of telmisartan in different co-surfactants was investigated and a higher solubility was found in Transcutol HP $(48.53 \pm 2.75 \mathrm{mg} / \mathrm{ml})$ than propylene glycol $(8.03 \pm 1.45 \mathrm{mg} / \mathrm{ml})$, polyethylene glycol $400(5.32 \pm 1.04 \mathrm{mg} / \mathrm{ml})$ and glycerol $(5.79 \pm 1.72 \mathrm{mg} / \mathrm{ml})$. So Transcutol HP was selected as cosurfactant which helps in further lowering of interfacial tension. Based on the solubility results the SEDDS formulations were developed employing varying concentrations of cinnamon oil (2070\%), Gelucire 44/14 (20-69\%), and Transcutol HP (4-27\%).

FTIR spectra of telmisartan (fig. 2) showed characteristic peaks of aliphatic C-H stretching at $2958 \mathrm{~cm}^{-1}, \mathrm{C}=0$ stretching at $1697 \mathrm{~cm}^{-1}, \mathrm{C}$ $\mathrm{N}$ stretching at $1126 \mathrm{~cm}^{-1}, \mathrm{C}=\mathrm{N}$ stretching at $1600 \mathrm{~cm}^{-1}$. The FTIR spectra of SEDDS (fig. 3) also showed all these characteristic peaks with minor shifts. These results from FTIR spectral analysis indicated that there was no chemical interaction between drug and excipients used in the formulation.

Ternary phase behavior investigations help to choose the proper concentration of excipients i.e. oil proportion and optimum S/CoS ratio in the formulation to produce emulsions with good stability [32]. As a fact, all surfactants are potentially irritant or are poorly tolerated [33], so large amounts of surfactants may cause irritation in the gastrointestinal tract [34]; systems which contain a higher proportion of essential oil should be preferred. Since the free energy required to form an emulsion is very low, due to the surfactant which reduces the interfacial tension, the formation is thermodynamically spontaneous. Surfactants also provide a mechanical barrier to coalescence [35]. After observing clarity, stability after $48 \mathrm{~h}$, it was noted that all formulations with $\mathrm{S} / \mathrm{CoS}$ ratio of 6:1 except TF15 and TF18 i.e. TF3, TF6, TF9 and TF12 produced stable emulsions, whereas the resultant emulsions of formulations with $\mathrm{S} / \mathrm{CoS}$ ratio of 2:1 showed phase separation and precipitation (results are shown in table 2). Among the $\mathrm{S} / \mathrm{CoS}$ ratio of 4:1, formulations TF2, TF5, and TF8 also produced stable emulsions. The reason for this may be due to the water solubility of Transcutol HP and its tendency to redistribute between aqueous phase and emulsion-water interface, leading to loss of solvent capacity resulting in an unstable emulsion.
However, with an increase of oil proportion over $40 \%$ to $70 \%$, the emulsification time was increased up to more than $200 \mathrm{sec}$. These visual observations indicated that higher the proportion of surfactant system, greater the spontaneity of emulsification. This may be due to excessive penetration of aqueous phase into the oil phase causing very large interfacial disruption and expulsion of droplets into the bulk aqueous phase [36]. SEDDS that passed this test in grades A and B were selected for further evaluation, as grades $A$ and $B$ formulations will remain as SNEDDS or SMEDDS when dispersed in G. I. fluids. All other SEDDS that were falling in grades C, $\mathrm{D}$ and $\mathrm{E}$ were discarded for further evaluation.

In agreement with P. Patil et al. (2007) [37], a slight increase in droplet size was observed for the TLS-loaded SEDDS. This can be attributed to the preferential dissolution of the drug in the interfacial film (formed by the surfactant and co-surfactant) that increases the interfacial tension. Moreover, the addition of the drug could induce surfactant aggregation, thus reducing its efficiency. The PDI values were below 0.5 indicated that the droplets were uniform in size. The $\zeta$-potential is correlated to the electrostatic repulsion and aggregation of the droplets. High positive or negative $\zeta$-potential values (higher electrostatic repulsive forces) arrest coalescence, thus enabling stability of the emulsions [38-40]. The negative charges were due to the presence of free fatty acids in the surfactant $[19,28]$. The droplet sizes of all the optimized formulations except TF12 were below $250 \mathrm{~nm}$ suggested SMEDD formulations. Again among SMEDDS, the formulation TF9 incorporate high proportions of oil as compared to conventional SMEDD formulations where the later is prepared by incorporating a large amount of surfactant or surfactant-cosurfactant mixture $(>70 \%)$. The droplet size of TF9 with telmisartan was found to be $150.72 \pm 3.64 \mathrm{~nm}$ (fig. 5) with PDI of 0.290 . The zeta potential of the emulsion developed by TF9 was found to be $-4.58 \pm 0.96 \mathrm{mV}$ (fig. 6 ). The conductivity of the emulsion was $0.200 \mathrm{mS} / \mathrm{cm}$, which means the emulsion was fine oil in water (conductivity $>10 \mu \mathrm{S} / \mathrm{cm}$ ) [27].

The stable SMEDDS formulations exposed to different $\mathrm{pH}$ media such as enzyme-free SGF ( $\mathrm{pH} 1.2)$, enzyme-free SIF ( $\mathrm{pH}$ 6.8) and distilled water to mimic the in vivo conditions revealed no precipitation or phase separation indicating all the formulations were found to be robust towards different $\mathrm{pH}$ conditions (fig. 7). However, the formulations were robust over the wider degree of dilution without any signs of drug precipitation and phase separation.

The droplet size increased with no significant changes of the $\zeta$ potential after three cooling and heating cycles. Moreover, the formulation didn't exhibit any drug precipitation or phase separation during the whole process. No marked difference of droplet size was observed for formulations stored at $4{ }^{\circ} \mathrm{C}$ or $25{ }^{\circ} \mathrm{C}$ (table 5). The above findings indicated that this telmisartan loaded formulation is thermodynamically stable.

The reason for higher cloud point temperature may be attributed to the solubility of the drug in oil and surfactant system, the optimized ratio of S/CoS and/or surfactants with higher HLB values. This infers good thermal stability of all the tested formulations. Above $76{ }^{\circ} \mathrm{C}$, phase separation and precipitation was observed, this is due to dehydration of surfactant mixture [23].

The drug release from SMEDDS was significantly greater than that of the telmisartan suspension. In 2 h, the SMEDDS TF6, TF8, TF9 and TF12 released more than $80 \%$ of the drug in comparison to $31.5 \%$ of the telmisartan from suspension. The formulations TF9 and TF12 released almost all drug ( $>95 \%$ ) in compared to other SMEDDS, with 
just a small difference among the different SMEDDS that are consistent with the droplet sizes. In addition, the release from SMEDDS was faster, further supporting the hypothesis that microscale emulsions can improve the release of lipophilic drugs. The drug release pattern of SMEDDS reveals that the highest drug release was observed with TF9 formulation after $60 \mathrm{~min}$. that could be due to proper compromise between proportions of oil and surfactant in the system. Though the formulations TF2, TF3 and TF6 produced emulsions with better spontaneity and more clarity, these formulations showed $36.29 \pm 3.91 \%, 41.61 \pm 2.17 \%$ and $59.26 \pm 2.62 \%$ drug release respectively, this may be due to high surfactant proportion in the formulation. However, the high surfactant proportion is usually concomitant with a higher probability of surfactant migration into surrounding aqueous media upon dispersion which is supposed to form micelles that trap free drug inside, with subsequent hindrance in drug release [33]. The drug release pattern from TF9 formulation followed first order up to $1 \mathrm{~h}$.

Results of the pharmacokinetic study showed that the $\mathrm{C}_{\max }$ and $\mathrm{AUC}_{(0-8 \mathrm{~h})}$ of TLS in SMEDDS increased by 1.78-fold and 2.38 fold respectively compared to the TLS suspension. Additionally, the TLS in SMEDDS was absorbed more rapidly and reached its peak concentration faster $(p<0.05)$. The absorption of telmisartan from SMEDDS resulted in a 2.4-fold increase in bioavailability compared with the suspension formulation.

\section{CONCLUSION}

In the present study, a novel SMEDDS was successfully designed as a stable, high essential oil ratio (40\%) and high drug-loaded (approximate 20\%) formulation for the solubility and dissolution rate enhancement of practically water insoluble drug, telmisartan. The formulation composition and $\mathrm{pH}$ of the emulsifying medium significantly impacted the droplet size. The stability study confirmed that the SMEDDS formulations could withstand various storage conditions with excellent stability. The in vitro drug release study demonstrated that the release from SMEDDS was more efficient when compared with the drug suspension. Also in vivo studies for clinical purpose, SMEDDS showed significantly greater extent of absorption than the suspension formulation. The relative bioavailability of SMEDDS to the suspension formulation $(20 \mathrm{mg} / \mathrm{ml})$ was $238 \%$. Under these circumstances, the present SMEDDS would be a promising novel system to improve the aqueous solubility of poorly soluble drug and potentially the bioavailability.

\section{ACKNOWLEDGEMENT}

The authors are thankful to GITAM Institute of Pharmacy, GITAM Deemed to be University, Visakhapatnam, India for providing the necessary facilities to carry out these studies. The authors are also thankful to Dr. Reddy's Laboratory, Hyderabad, India for kindly providing gift sample of drug Telmisartan and thankful to Gattefosse India Pvt. Ltd, Mumbai, India for generously donating the gift samples of Gelucire 44/14 and Transcutol-HP for carrying out the research work.

\section{AUTHORS CONTRIBUTIONS}

All the author have contributed equally

\section{CONFLICT OF INTERESTS}

Authors declared that there is no conflict of interest

\section{REFERENCES}

1. Wang L, Dong J, Chen J, Eastoe J, Li Xuefeng. Design and optimization of a new self-nanoemulsifying drug delivery system. J Colloid Interface Sci 2009;330:443-8.

2. Hoffman A, Dahan A. Rationalizing the selection of oral lipid based drug delivery systems by an in vitro dynamic lipolysis model for improved oral bioavailability of poorly water soluble drugs. J Controlled Release 2008;129:1-10.

3. Nagarsenker MS, Date A. Design and evaluation of selfnanoemulsifying drug delivery systems (SNEDDS) for cefpodoxime proxetil. Int J Pharm 2007;329:166-72.

4. Desai PP, Date AA, Patravale VB. Overcoming poor oral bioavailability using nanoparticle formulations-opportunities and limitations. Drug Discovery Today Tech 2012;9:e87-95.
5. Takagi T, Ramachandran C, Bermejo M, Yamashita S, Yu LX, Amidon GL. A provisional biopharmaceutical classification of the top 200 oral drug products in the United States, Great Britain, Spain, and Japan. Mol Pharm 2006;3:631-43.

6. Kawabata Y, Wada K, Nakatani M, Yamada S, Onoue S. Formulation design for poorly water-soluble drugs based on biopharmaceutics classification system: basic approaches and practical applications. Int J Pharm 2011;420:1-10.

7. Williams HD, Trevaskis NL, Charman SA, Shanker RM, Charman WN, Pouton CW. et al. Strategies to address low drug solubility in discovery and development. Pharmacol Rev 2013;65:315-499.

8. Palmer AM. New horizons in drug metabolism, pharmacokinetics and drug discovery. Drug News Perspectives 2003;16:57-62.

9. Weuts I, Kempen D, Decorte A, Verreck G, Peeters J, Brewster $\mathrm{M}$, et al. Phase behaviour analysis of solid dispersions of loperamide and two structurally related compounds with the polymers PVP-K30 and PVP-VA64. Eur J Pharm Sci 2004;22:375-85.

10. Ammar HO, Salama HA, Ghorab M, Mahmoud AA. Implication of inclusion complexation of glimepiride in cyclodextrin-polymer systems on its dissolution, stability and therapeutic efficacy. Int J Pharm 2006;20:53-7.

11. Aungst BJ. Novel formulation strategies for improving oral bioavailability of drugs with poor membrane permeation or presystemic metabolism. J Pharm Sci 1993;82:979-87.

12. Hiendrawan S, Hartanti AW, Veriansyah B, Widjojokusumo E, Tjandrawinata RR. Solubility enhancement of ketoconazole via salt and cocrystal formation. Int J Pharm Pharm Sci 2015;7:160-4.

13. Odeberg JM, Kaufmann P, Kroon KG, Hoglund P. Lipid drug delivery and rational formulation design for lipophilic drugs with low oral bioavailability, applied to cyclosporine. Eur J Pharm Sci 2003;20:375-82.

14. Humberstone AJ, Charman WN. Lipid-based vehicles for the oral delivery of poorly water soluble drugs. Adv Drug Delivery Rev 1997;25:103-28.

15. Constantinides PP. Lipid microemulsions for improving drug dissolution and oral absorption: physical and biopharmaceutical aspects. Pharm Res 1985;12:161-72.

16. Sisinthy SP, Sarah CYL, Rao NK. Optimization of coconut oil based selfmicro emulsifying drug delivery systems of olmesartan medoxomil by simplex centroid design. Int J Appl Pharm 2016;8:47-52.

17. Bajaj A, Rao MRP, Pardeshi A, Sali D. Nanocrystallization by evaporative antisolvent technique for solubility and bioavailability enhancement of telmisartan. AAPS Pharm Sci Tech 2012;13:1331-40.

18. Lawrence MJ, Rees GD. Microemulsion-based media as novel drug delivery systems. Adv Drug Delivery Rev 2000;64:175-93.

19. Balakrishnan P, Lee BJ, Oh DH, Kim JO, Lee YI, Kim DD, et al. Enhanced oral bioavailability of Coenzyme Q10 by selfemulsifying drug delivery systems. Int J Pharm 2009;374:66-72.

20. Nazzal S, Smalyukh II, Lavrentovich OD, Khan MA. Preparation and in vitro characterization of a eutectic based semisolid selfnanoemulsified drug delivery system (SNEDDS) of ubiquinone: mechanism and progress of emulsion formation. Int J Pharm 2002;235:247-65.

21. Villar AM, Naveros BC, Campmany AC, Trenchs MA, Rocabert $\mathrm{CB}$, Bellowa LH. Design and optimization of selfnanoemulsifying drug delivery systems (SNEDDS) for enhanced dissolution of gemfibrozil. Int J Pharm 2012;431:161-75.

22. Khoo SM, Humberstone AJ, Porter CJH, Edwards GA, Charman WN. Formulation design and bioavailability assessment of lipidic self-emulsifying formulations of halofantrine. Int J Pharm 1998;167:155-64.

23. Elnaggar YSR, El-Massik MA, Abdallah OY. Self-nanoemulsifying drug delivery systems of tamoxifen citrate: design and optimization. Int J Pharm 200;380:133-41.

24. Shafiq S, Shakeel F, Talegaonkar S, Ahmad FJ, Khar RK, Ali M. Development and bioavailability assessment of ramipril nanoemulsion formulation. Eur J Pharm Biopharm 2007; 66:227-43.

25. Zhang P, Liu Y, Feng N, Xu J. Preparation and evaluation of selfmicroemulsifying drug delivery system of oridonin. Int J Pharm 2008;355:269-76. 
26. Kang BK, Lee JS, Chon SK, Jeong SY, Yuk SH, Khang G, et al. Development of self-microemulsifying drug delivery systems (SMEDDS) for oral bioavailability enhancement of simvastatin in beagle dogs. Int J Pharm 2004;274:65-73.

27. Anton N, Benoit JP, Saulnier P. Design and production of nanoparticles formulated from nano-emulsion templates-a review. J Controlled Release 2008;128:185-99.

28. Mc Conville C, Friend D. Development and characterisation of a self-microemulsifying drug delivery systems (SMEDDSs) for the vaginal administration of the antiretroviral UC-781. Eur J Pharm Biopharm 2013;83:322-9.

29. Davies JT. Drop sizes of emulsions related to turbulent energydissipation rates. Chem Eng Sci 1985;40:839-42.

30. Becher P. Hydrophile-lipophile balance (HLB)-history and recent developments. J Dispersion Sci Tech 1984;5:81-96.

31. Pouton CW. Lipid formulations for oral administration of drugs: nonemulsifying, self emulsifying and self microemulsifying drug delivery systems. Eur J Pharm Sci 2000;11:S93-8.

32. Patel AR, Vavia PR. Preparation and in vivo evaluation of SMEDDS (self microemulsifying drug delivery system) containing fenofibrate. AAPS J 2007;9:E344-52.

33. Pouton CW, Porter CJ. Formulation of lipid-based delivery systems for oral administration: materials, methods and strategies. Adv Drug Delivery Rev 2008;60:625-37.
34. Anton N, Gayet P, Benoit JP, Saulnier P. Nano-emulsions and nanocapsules by the PIT method: an investigation on the role of the temperature cycling on the emulsion phase inversion. Int J Pharm 2007;344:44-52.

35. Craig DQM, Barker SA, Banning D, Booth SW. An investigation into the mechanisms of self-emulsification using particle size analysis and low frequency dielectric spectroscopy. Int J Pharm 1995;114:103-10.

36. Pouton CW. Formulation of self-emulsifying drug delivery systems. Adv Drug Delivery Rev 1997;25:47-58.

37. Patil P, Patil V, Paradkar A. Formulation of a self-emulsifying system for oral delivery of simvastatin: in vitro and in vivo evaluation. Acta Pharm 2007;57:111-22.

38. Lindenberg M, Kopp S, Dressman JB. Classification of orally administered drugs on the World Health Organization model list of essential medicines according to the biopharmaceutics classification system. Eur J Pharm Biopharm 2004;58:265-78.

39. Bandyopadhyay S, Katare OP, Singh B. Optimized self nanoemulsifying systems of ezetimibe with enhanced bioavailability potential using long chain and medium chain triglycerides. Colloids Surf B 2012;100:50-61.

40. Giongo AL, Vaucher RDA, Ourique AF, Steffler MCR, Frizzo CP, Hennemman B. Development of nanoemulsion containing Pelargonium graveolens oil: characterization and stability study. Int J Pharm Pharm Sci 2016;8:271-6. 